\title{
Admission rates for schizophrenia in The Netherlands: an urban/rural comparison
}

\author{
Peen J, Dekker J. Admission rates for schizophrenia in The Netherlands: \\ an urban/rural comparison. \\ Acta Psychiatr Scand 1997: 96: 301-305. (C) Munksgaard 1997. \\ This article examines admission rates for schizophrenia in terms of degree \\ of urbanization. Patient data was obtained from the Dutch psychiatric \\ register. The scale of urbanization used had five categories and was utilized \\ to establish the degree of urbanization in each municipality $(n=647)$. \\ Admission rates showed a significant positive correlation with the degree of \\ urbanization in the 15-34 years and 35-54 years age groups for both sexes. \\ The average duration of hospitalization and the average number of \\ readmissions showed no association with the degree of urbanization. Taken \\ as a whole, these utilization rates provide evidence of a much higher \\ incidence of schizophrenia in the most urbanized municipalities of \\ The Netherlands.
}

\author{
J. Peen, J. Dekker \\ Research, Training and Development Department, \\ Amsterdam Psychiatric Hospital, Amsterdam, \\ The Netherlands \\ Key words: epidemiology; schizophrenia; urbanization \\ J. Peen, Psychiatric Hospital Amsterdam, Postbus \\ 75848, 1070 AV Amsterdam. The Netherlands \\ Accepted for publication January 18, 1997
}

\section{Introduction}

Many studies on urban/rural differences in the incidence and prevalence of schizophrenia show slightly higher rates in urban areas of industrialized countries (1-3). A major epidemiological catchment area study showed an $80 \%$ higher prevalence rate for schizophrenia in urban areas. However, this difference was not statistically significant (4). There are exceptions to this pattern, an example being the high prevalence found in an Irish rural area (5). Despite this type of exception, there is still a debate about the causes of schizophrenia relating to living in cities. Lewis et al. (6) showed that growing up in a city results in an increased risk of schizophrenia. Other explanations are based upon migration processes. One study suggests that schizophrenics and latent schizophrenics in cities probably drift towards deprived areas due to downward social mobility (7). However, Torrey and Bowler (3) believe that a comparable rural/ urban social drift is unlikely. This phenomenon would not therefore explain the tendency towards higher rates of schizophrenia in urban areas. Another hypothesis along similar lines is the social residue hypothesis. This theory suggests that healthy individuals move out of impoverished areas and probably also out of cities, leaving behind a residual population with a high prevalence of schizophrenia (8). Freeman concludes in his review (9) that urbanization is probably not an independent aetiological factor, but that unexplained differences can be explained in terms of selective migration as well as by inadequate correction for social class. Studies on urban/rural differences in (first) admission rates for schizophrenia are scarce. In Italy, no significant difference was found for first admission rates for schizophrenia, although the total rate of admissions for schizophrenia was higher in the rural area that was studied (10). In The Netherlands, Sytema (11) did find a positive correlation in a rural province between incidence rates for schizophrenia and urbanization over a 2-year period. The effect of urbanization remained after controlling for the distance to the location where the study took place.

Almost all urban/rural comparisons are based on two - sometimes three - areas which all represent a certain degree of urbanization. In this study, we were able to determine the relationship for a whole country (i.e. The Netherlands) between the urbanization of municipalities and the admission 
rates to psychiatric hospitals of the inhabitants of those municipalities. Length of stay and readmission rates were also studied in order to account for any differences in terms of urbanization.

\section{Materiais and methods}

In 1991 it was established how many patients (over 15 years of age) with schizophrenia (ICD9) in all of the municipalities were admitted to the in-patient psychiatric facilities of the General Psychiatric Hospitals (GPH) and to the Psychiatric Teaching Clinics (PTC) of General Hospitals. In 1991, there were 50 GPHs (with a total capacity of approximately 21900 beds) and 6 PTCs (with 1100 beds in total). A national registration system (Patient Registration for In-patient Mental Health Care) records all admissions to GPHs and PTCs, together with the addresses of patients at the time of admission. Psychiatric admissions to general hospitals are not included in the register. However, in The Netherlands, schizophrenic patients are only admitted to general hospitals in a few cases (12). We used the number of patients with schizophrenia admitted to in-patient facilities to calculate the patient rate per 1000 resident members of the population of each municipality. The study covered 23644 psychiatric patients who were admitted in 1991. Of this group, 6803 patients had already been admitted one or more times during the 2 years prior to 1991. In order to eliminate the effect of the 'revolving-door' patients, the latter group was excluded from subsequent analyses. Of the remaining patients $(n=16841)$, only those with a diagnosis of schizophrenia (ICD-9-code 295) were selected $(n=1682)$. The following variables for these patients were included in the study: sex, age, municipality, length of stay and number of readmissions prior to 31 December 1993. Discharge data were available for a period of 2 years after admission, resulting in a maximum length of stay of 2 years. The average number of readmissions prior to 31 December 1993 was determined solely on the basis of the group of patients who were discharged in 1991. This was done in order to reduce the influence of length of stay on the likelihood of being readmitted.

The Dutch Central Statistical Office has recently started to determine the degree of urbanization for each municipality, revising its findings annually (13). The simple, single-dimensional and numerical unit of measurement that it uses for this purpose is 'area address density'. In simple terms, the number of addresses in the immediate vicinity is determined for every address (of a residence, business or organization) in The Netherlands. An address here refers to a postal address, i.e. indivi- dual house/flat number, street name, town and postal code. The area address density is calculated using a grid of squares measuring 500 by $500 \mathrm{~m}$ each. The address density for each address in a square is then determined as the number of addresses in the square in which the address is located, plus the number of addresses in the 12 squares for which the centres are $1 \mathrm{~km}$ from the centre of the square in which the address is situated. The area address density for a municipality is determined by taking the average for the address density of all the individual addresses in a municipality.

The area address density has some advantages over the widely used population density, especially when it is applied at the level of municipalities. Municipalities differ in terms of urbanized area. This means that it is possible for the population densities of two municipalities to be very different, while the actual living conditions of the inhabitants are on average the same. The area address density partially corrects for this phenomenon, since the calculation also includes addresses in areas adjacent to municipalities. Another difference is that the addresses of businesses and organizations are incorporated in the area address density. In contrast to population density, all economic activities (i.e. all buildings) are incorporated. The drawback of the population density measure is that it only includes places of residence, with the consequence that industrial areas receive the same rating as, for example, agriculture. Despite these differences, there is still a strong correlation between these two measures of urbanization $(0.85, P<0.001$; $n=647$ ).

After determining the average area address density for every municipality, the Central Statistical Office placed each municipality in one of the following five categories: very highly urbanized, highly urbanized, moderately urbanized, not very urbanized, not urbanized. Table 1 shows the numbers of inhabitants for each category of municipality.

The inhabitants of The Netherlands are quite evenly distributed with regard to the urbanization categories.

Confidence intervals were computed in order to compare the admission rates for the five urbanization categories. The effect of urbanization on the admission rates of the urbanization categories was analysed by analysis of variance (ANOVA). Average length of stay and the average number of readmissions according to age and sex were analysed using Student $t$-tests. In every age/sex category, each category of urbanization was compared with the total group of patients from the other four categories. 
Table 1. Inhabitants of The Netherlands categorized according to degree of urbanization

\begin{tabular}{|c|c|c|c|c|c|}
\hline Urbanization & $\begin{array}{c}\text { Number of } \\
\text { addresses } \mathrm{km}^{-2}\end{array}$ & $\begin{array}{c}\text { Number of } \\
\text { municipalities }\end{array}$ & Men & Women & Total \\
\hline Very highly urbanized & $>2500$ & 12 & 1316444 & 1394673 & 2711117 \\
\hline Highly urbanized & $1500-2500$ & 41 & 1513047 & 1581447 & 3094494 \\
\hline Moderately urbanized & $1000-1500$ & 87 & 1544391 & 1594730 & 3139121 \\
\hline Not very urbanized & $500-1000$ & 181 & 1551076 & 1558415 & 3109491 \\
\hline Not urbanized & $<500$ & 326 & 1493153 & 1461234 & 2954387 \\
\hline The Netherlands & & 647 & 7418111 & 7590499 & 15008610 \\
\hline
\end{tabular}

\section{Results}

Table 2 shows the ratios (number-of-patients admitted per 100000 inhabitants) and the absolute numbers of patients admitted with schizophrenia, categorized according to degree of urbanization.

For men and women in the 15-34 years and 35-54 years age categories, the rates for the very highly urbanized category differed from those for the less urbanized categories. In addition, there were only two cases in which there was no overlap of confidence intervals between successive categories. For men in the 15-34 years age group, the not very urbanized category and the not urbanized category differed from their preceding counterparts. The effect of urbanization over the five categories was significant for men and women in the 15-34 years age group $(P<0.001$ and $P<0.01$, respectively $)$ and in the 35-54 years age group $(P<0.001$ and $P<0.001$, respectively).

More male subjects were admitted with schizophrenia than females (men were mainly admitted when young and women when middle-aged).

Table 3 shows the average lengths of stay and the average number of readmissions in 1992 and 1993 for patients discharged in 1991.

The average length of stay and the readmission figures (Table 3) were compared for each cell with the rest of the same column ( $t$-test). The men in the 15-34 years age group in the most urbanized category were treated for shorter periods of time than the rest of the male subjects in that age group. Women in the 15-34 years age group in the moderately urbanized category and women in the 35-44 years age group in the not urbanized category were also treated for shorter periods of time than their counterparts in the other urbanization categories. The analysis of the average numbers of readmissions showed no significant results.

\section{Discussion}

In The Netherlands there is a positive correlation between the risk of hospital admission for schizophrenia and the degree of urbanization. Admission rates in the most urbanized category were higher than in less urbanized categories for both sexes in the 15-34 and 35-54 years age groups. There were also significant overall effects of urbanization on the admission rates in these groups. It is not possible to justify - on the basis of the analyses relating to duration of stay and readmission numbers - the alternative explanation that, in highly urbanized municipalities, patients with schizophrenia are treated for shorter lengths of time and are admitted more often.

An initial limitation of this study relates to the conclusions which can be drawn on the basis of the admission rates. On the basis of these findings, it

Table 2. Number of admissions per 100000 inhabitants and absolute number of patients admitted with schizophrenia, categorized according to degree of urbanization

\begin{tabular}{|c|c|c|c|c|c|c|c|c|c|c|c|c|}
\hline \multirow[b]{3}{*}{ Urbanization } & \multicolumn{4}{|c|}{$15-34$ years of age } & \multicolumn{4}{|c|}{$35-54$ years of age } & \multicolumn{4}{|c|}{$\geqslant 55$ years of age } \\
\hline & \multicolumn{2}{|r|}{ Men } & \multicolumn{2}{|r|}{ Women } & \multicolumn{2}{|r|}{ Men } & \multicolumn{2}{|r|}{ Women } & \multicolumn{2}{|r|}{ Men } & \multicolumn{2}{|r|}{ Women } \\
\hline & $n$ & Rate & $n$ & Rate & $n$ & Rate & $n$ & Rate & $n$ & Rate & $n$ & Rate \\
\hline Very highly urbanized & 235 & $48.2(42.0-54.4)$ & 85 & $18.1(14.2-21.9)$ & 129 & $37.1(30.7-43.5)$ & 96 & $29.5(23.6-35.2)$ & 24 & $8.7(5.2-12.2)$ & 55 & $13.7(10.1-17.4)$ \\
\hline Highly urbanized & 137 & $26.2(21.8-30.6)$ & 48 & $9.4(6.8-12.1)$ & 79 & $18.9(14.7-23.1)$ & 58 & $14.2\{10.5-17.8\}$ & 19 & $6.4(3.5-9.3)$ & 40 & $10.1(7.0-13.2\}$ \\
\hline Moderately urbanized & 113 & $22.6(18.4-26.8)$ & 27 & $5.5(3.4-7.6)$ & 68 & $15.3(11.7-18.9)$ & 57 & $13.1(9.7-16.5)$ & 5 & $1.7(0.2-3.2)$ & 31 & $8.1(5.3-11.0)$ \\
\hline Not very urbanized & 68 & $13.6(10.4-16.9)$ & 29 & $6.2(3.9-8.4)$ & 45 & $10.1(7.1-13.0)$ & 47 & $11.0(7.8-14.1)$ & 14 & $4.7(2.3-7.2)$ & 24 & $6.6(4.0-9.3)$ \\
\hline Not urbanized & 46 & $9.8(6.9-12.6)$ & 21 & $4.8(2.8-6.9)$ & 28 & $6.5(4.1-8.9)$ & 26 & $6.5(4.0-9.0)$ & 9 & $3.1(1.1-5.1)$ & 19 & $5.6(3.1-8.1)$ \\
\hline The Netherlands & 599 & $24.2(22.2-26.1)$ & 210 & $8.8(7.7-10.0)$ & 349 & $16.7(15.0-18.5)$ & 284 & $14.2(12.6-15.9)$ & 71 & $4.9(3.7-6.0)$ & 169 & $9.0(7.6-10.3)$ \\
\hline
\end{tabular}


Table 3. Average length of stay for patients admitted with schizophrenia within 2 years after admission, and the average numbers of readmissions in 1992 and 1993 (of patients discharged in 1991) categorized according to age, sex and degree of urbanization

\begin{tabular}{|c|c|c|c|c|c|c|c|c|c|c|c|c|}
\hline \multirow[b]{3}{*}{ Urbanization } & \multicolumn{4}{|c|}{$15-34$ years of age } & \multicolumn{4}{|c|}{$35-54$ years of age } & \multicolumn{4}{|c|}{$\geqslant 55$ years of age } \\
\hline & \multicolumn{2}{|c|}{ Men } & \multicolumn{2}{|c|}{ Women } & \multicolumn{2}{|c|}{ Men } & \multicolumn{2}{|c|}{ Women } & \multicolumn{2}{|c|}{ Men } & \multicolumn{2}{|c|}{ Women } \\
\hline & $A^{a}$ & $\mathrm{~B}^{b}$ & A & B & $A$ & B & A & B & $A$ & $B$ & $A$ & B \\
\hline Very highly urbanized & $111^{*}$ & 1.2 & 87 & 0.9 & 82 & 1.4 & 112 & 1.1 & 59 & 0.8 & 111 & 0.8 \\
\hline Highly urbanized & 154 & 1.0 & 96 & 0.6 & 83 & 1.4 & 152 & 0.8 & 175 & 2.5 & 220 & 0.6 \\
\hline Moderately urbanized & 154 & 1.0 & $48^{* *}$ & 1.0 & 110 & 1.6 & 118 & 0.6 & 141 & 0.8 & 141 & 1.1 \\
\hline Not very urbanized & 108 & 1.3 & 95 & 0.6 & 146 & 1.2 & 106 & 0.8 & 60 & 0.6 & 101 & 0.7 \\
\hline Not urbanized & 156 & 2.0 & 139 & 1.8 & 133 & 0.8 & $65^{* *}$ & 1.0 & 70 & 1.5 & 169 & 0.6 \\
\hline The Netherlands & 131 & 1.2 & 90 & 0.9 & 100 & 1.3 & 116 & 0.9 & 95 & 1.1 & 143 & 0.8 \\
\hline
\end{tabular}

${ }^{a} A$, average length of stay.

${ }^{b} \mathrm{~B}$, average number of readmissions.

${ }^{*} P<0.05 ;{ }^{*} P<0.01$

cannot be stated that psychiatric morbidity in cities is higher than that in rural areas. Admission rates are indeed related to true morbidity, but they are probably also influenced by referral patterns, helpseeking behaviour and distance from psychiatric facilities (14). For instance, Keatinge found that inhabitants of rural areas had a more negative attitude towards psychiatry than urban dwellers (15). Patients in rural areas were more often looked after by their families and friends. It is doubtful whether this pattern is also found in cases of severe disorders such as schizophrenia. As the distance from psychiatric facilities is on average lower for people living in urban areas than for those living in rural areas, this could explain the urbanization effect. Studies in which urbanization and distance to the facilities are analysed together are scarce. Davey \& Giles (16) found that distance to mental health facilities was a significant factor in the use of those facilities when urban residence was controlled for. In the province of Drenthe, The Netherlands, Sytema found that both urbanization and distance correlated significantly with the treated incidence of schizophrenia (11). It should be mentioned that, on average, the distance to the nearest psychiatric facility is relatively small in a country like The Netherlands, which is densely populated. The influence of distance from facilities on utilization rates is not as yet very clear.

The concentration of schizophrenics in the most urbanized category is reminiscent of the concentration that is often found in segregated inner-city areas as a result of social drift processes (7). When they examined the difference between states and regions in the USA, Torrey \& Bowler found that rural/urban social drift was an unlikely explanation for higher prevalence rates of schizophrenia in the urban regions (3). It is possible that the large distances in a country the size of the USA mean that rural/urban social drift is less relevant. However, this theory certainly cannot be excluded in a small, industrialized country such as The Netherlands. Research in the Netherlands has shown that the percentage of individuals in the lowest socio-economic status (SES) class is highest in very large cities ${ }^{\mathrm{a}}$. In addition, it is possible that people who complete higher education in the city and who have worked their way up the socioeconomic ladder leave the city and move to surrounding municipalities, while less fortunate individuals are unable to leave. Assuming that the people who leave the city have a lower morbidity than the incoming group and individuals born in the city, this selection process could result in a residual population with a relatively high incidence of schizophrenia. Further research into the mobility of schizophrenic patients and premorbid mobility would appear to be the best way forward in attempting to explain the high incidence figures in the most urbanized municipalities. Until now, there have been no large-scale studies of true morbidity in The Netherlands for determining whether there are urban/rural differences in the proportion of treated cases.

\section{References}

1. Dohrenwend B. Socio-cultural and social-psychological factors in the genesis of mental disorders. J Health Soc Behav 1975: 16: 365-392.

2. Widerlöy B, Borga P, Cullberg J, Stefansson CG, LINDQVIST G. Epidemiology of long-term functional

${ }^{a}$ Dekker J, Peen J, Gardien R, Wijdenes W. Urbanisation and psychiatric admission rates in The Netherlands. Unpublished article. 
psychosis in three different areas in Stockholm County. Acta Psychiatr Scand 1989: 80: 40-46.

3. Torrey EF, Bowler A. Geographical distribution of insanity in America: evidence for an urban factor. Schizophr Bull 1990: 16: 591-604.

4. Blazer D, George LK, Landerman R et al. Psychiatric disorders. A rural/urban comparison. Arch Gen Psychiatry 1985: 42: 651-656.

5. Torrey EF. Prevalence studies of schizophrenia. $\mathrm{Br}$ J Psychiatry 1994: 150: 598-608.

6. Lewis G, David A, Andréasson S, Allebeck P. Schizophrenia and city life. Lancet 1992: 340: 137-140.

7. Dunham W. Community and schizophrenia. Detroit: Wayne State University Press, 1965.

8. Freeman HL, Alpert M. Prevalence of schizophrenia in an urban population. Br J Psychiatry 1986: 149: 603-611.

9. Freeman HL. Schizophrenia and city residence. $\mathrm{Br}$ J Psychiatry 1994: 164 (suppl. 23): 39-50.

10. Thornicroft G, Bisoffi G, de Salvia D, Tansella M. Urban-rural differences in the association between social deprivation and psychiatric service utilization in schizophrenia and all diagnoses: a case-register study in Northern Italy. Psychol Med 1993: 23: 487-496.

11. Sytema S. Social indicators and psychiatric admission rates: a case-register study in The Netherlands. Psychol Med 1991: 21: 177-184.

12. Selten JP, Suben N. First admission for schizophrenia in immigrants to The Netherlands. Soc Psychiatry Psychiatr Epidemiol 1994: 29: 71-77.

13. den Dulk CJ, van de Stadt H, Vliegen JM. Een nieuwe maatstaf voor stedelijkheid: de omgevingsadressendichtheid (A new unit of measurement for urbanisation: area address density). Maand Bevolking 1992: 40: 14-27.

14. Goldberg D, HuXley P. Mental illness in the community. London: Tavistock, 1980.

15. Keatinge C. Community factors influencing psychiatric hospital utilization in rural and urban Ireland. Commun Mental Health J 1987: 23: 192-203.

16. Davey SC, GILes GG. Spatial factors in mental health care in Tasmania. Soc Sci Med 1979: 13: 87-94. 